\title{
ELBASANI në shekuj, qëmtuar nga pena të arta franceze
}

Alfred Kopani

"Ky qytet ka famë, se ka qenë edhe atdheu i shumë dijetarëve të moçëm"

E Çelebi.

Gjithçka e vyer, e shenjtë shpirtërore dhe patriotike, lartësohet përgjatë një Antologjie përmbledhëse e studimore, të përkthyesit të talentuar Fotaq Andrea, bashkëpunëtor e pasues i mjeshtrit të madh të përkthimeve, Jusuf Vrioni, në librin e dalë para pak kohe, Pena të arta franceze për shqiptarët (1332-2007), një volum prej rreth 800 faqesh. Para së gjithash, meritojnë të kryesohen shkrimet e portreteve, të ngritura në majat e kësaj vepre, filluar me Skënderbejadën (disa materiale për herë të parë); për figura madhore që kanë bërë histori: Kostandin Kristoforidhi, Ali Pashë Tepelena, Lordi Bajron, Mehmet Aliu, Konteshë Dora d' Istria, Vaso Pasha, Jeronim De Rada, Faik Bej Konica, Fan S. Noli, Luigj Gurakuqi, Bubulima, Tefta Tashko Koço, shënjtorja Nënë Tereza, si dhe flamurtari i frankofonisë shqiptare, Jusuf Vrioni dhe sfinksi i letrave shqipe, Ismail Kadare.

Përgjatë historisë shekullore, Elbasani, si mbarë trojet iliro-shqiptare, është përballur gjithmonë me alternativën historike, ose drejt shuarjes, përballë dyndjeve të furishme, ose drejt tkurrjes, e qëndresës së mbijetesës, paguar me çdo çmim. Kontributi i Elbasanit do jepte frytet e veta në Evropë e më gjerë, duke u vlerësuar e nderuar, veçanërisht për atë që ka dhënë shumë për të tjerët e pak për veten. Dhe një nxitje për t'u thelluar më shumë në këtë drejtim është libri në fjalë, ku citimet me një vërtetësi të thekshme të njëqind e dyzet mjeshtrave francezë, kanë qëmtuar me kujdes, virtytin, krenarinë, dinjitetin dhe fisnikërinë shqiptare në përgjithësi dhe atë elbasanase në veçanti. Le të veçojmë shkrimet perlë të mjeshtrave të penës: Hygo, Dyma, Flober, Zh.Vern, 


\section{Albanon}

\section{Revistë kulturore}

Apoliner etj.; jehonat e eseve filozofike të Montenjit, Lamartinit e Volterit; penelatat e piktorëve: Koro, Delakrua, Dypre, Lear, Valerio etj., mbresat, udhëpërshkrimet nga diplomatë e njerëz të respektuar: Gijom Adam, Ogust Dozon, Viktor Berard, Fransua Pukëvil, Justin Godar, Robert d!Anzheli, Mathie Aref etj.

-Kryepeshkopi katolik i Tivarit, Gijom Adam (1270-1341)

..në një relacion dërguar mbretit të Francës, Filipit 7-të, më 1332, shkruan se "në librat e tyre (Arbëri), përdorin shkronjat latine, megjithëse kanë një gjuhë tjetër."

-Mario Rok (1875-1961), profesor në Ecole Normale Supérieure të Parisit, anëtar i Akademisë Mbretërore të Gjuhës e Letërsisë Franceze të Belgjikës, leksikograf i madh medievist, që botoi Fjalorin shqip të Frang Bardhit, i cili ka mbajtur lidhje të ngushta njëkohësisht edhe me rilindas e figura të njohura shqiptare.

Duke shprehur vështirësi në mungesën e gjetjes së librit shqip në dy dekadat e para të shek.XX, ai i drejtohet Mit'hat Frashëri, që t’i sigurojë, Fjalorin shqip të Kristoforidhit, botuar në Athinë më 1904. Studiuesi në fjalë, përmend Dorëshkrimin prej 37 fletësh në pergamenë shumë të bukur (Ashburnham 1167 i Laurentienës), si dokumentin më të lashtë në gjuhën shqipe, shkruar më bukur (1462).

Është folur e shkruar në kohë, si për lashtësinë, ashtu dhe për atë që nga shqipja e hershme kanë rrjedhur gjuhë të tjera. Pikërisht lidhur sa më sipër, autorë francezë japin dokumenta të vyera e të pakundërshtueshme. Ndër to një vend nderi zë

-Zhak Burkar (1891-1965), anëtar i Akademisë së Shkencave, gjeograf, udhëpërshkrues, oqeanograf, i cili me veprën e tij Shqipëria dhe shqiptarët (Paris, më 1921), hodhi baza shkencore të pakontestueshme në shkencën albanalogjike, ka sjellë dokumenta të vyera lidhur me tezën që nga gjuha shqipe kanë rrjedhur gjuhë të tjera. Ja se ç'thotë ai midis tjerash: "Nga njëri skaj te tjetri i Shqipërisë...., flitet një gjuhë e vetme: shqipja.... Megjithatë, trakishtja dhe ilirishtja, duket se i përkasin të njëjtit grup gjuhësor.......Tri dialekte ndeshen për t’u bërë gjuha letrare dhe e përgjithshme..., ai i Elbasanit $i$ vendosur harmonikisht midis gegërishtes dhe toskërishtes, ifolur lehtë nga të gjithë dhe që gëzon pozicionin qendror të këtij kryeqyteti të ardhshëm të Shqipërisë"!.... -Zakari Majani, doktor i Universitetit të Parisit, në punimin e tij, Shqiptarët dhe gjuha e tyre (Paris-1970), fakton sa më sipër dhe përkrah tezën se gjuha etruske është dialekt ilir dhe se shqipja ruan të paprekur bazën e vet ilire. E 
më poshtë, e quan shqipen një gjuhë që të shtang, sikurse të marrësh “drejte nga toka një copë ari... filologjik".

Për këtë, ai jep shembuj fjalësh arkaike bashkëkohëse të Iliadës e Mbretit të dytë të Romës Numa Pompilius(715-672). Emri i një populli ilir Triballoi - shpjegohet nëpërmjet shqipes ballë-majë, fjala etruske tur - jap, dhuroj; molosët - fjala malësor, prejardhur nga mal (ilirisht, etruskisht e shqip), emri çam, banor i çamërisë (Tshamëria) - sipas emrit të lumit Thyamis (sot Kalamas).

-Natali Klejer, studiuese pranë Qendrës Kombëtare Franceze të Kërkimit Shkencor, ka botuar studime të shumta për historinë e islamit e të bektashizmit në Shqipëri, duke e parë fenë të lidhur ngushtë me çështjen kombëtare. Në një nga shkrimet e saj (botuar në Revue des Mondes, 2004), ajo e cilëson leximin e shqipes gjatë Perandorisë osmane, "shije e një fruti të ndaluar". Midis të tjerash, ajo citon një legjendë: "Shqiptari i parë, e fshehu një ditë librin e vet brenda një lakre. Një lopë shkoi aty dhe hëngri gjthçka, prandaj dhe shqiptarët nuk kanë libra". Kalimi nga libri i shenjtë në librin kombëtar, sipas studiueses, zhvillohet midis viteve 1878-1908. Në vazhdën e përpjekjeve në prodhimin e shtypshkrimeve në gjuhën shqipe (duke lënë mënjanë dorëshkrimet), që hamendësohet rreth vitit 1555, me botimin e Mesharit të Gjon Buzukut, një kontribut të madh e të pazëvendësueshëm, ka dhënë gjuhëtari dhe përkthyesi i shek.XIX, Kostandin Kristoforidhi. Klejer, e quan atë "një shqiptar $i$ Elbasanit, që punoi personalisht për përhapjen e librave dhe praktikimin e leximit. Duhet cilësuar roli i ndërmarrjeve përkthimore në gjubën shqipe të bëra nga British and Foreing Bible Society të Londrës (rreth vitit 1816)".

-Ogust Dozon (1822-1880), konsull i Francës në Janinë, njëkohësisht ballkanolog dhe albanalog i njohur, botoi ndër të tjera veprën Manual $i$ gjuhës shqipe dhe Përralla shqiptare, libra me vlerë këto për kohën. Në Buletin de la Société de Géographie, Paris, 1875, ai boton Ekskursion në Shqipëri, ku përmend disa herë Elbasanin e rrethinat e tij. Gjatë udhëtimit nëpër luginën e Shkumbesë (Shkumbin), Dozon përshkruan fshatin prej 20 shtëpish Kiukos (Qukës), me dy hane dhe me një postë zaptijesh. "Pas 6 orë më tej dal në urën Bekiarit (Beqarit), nga ku shihet në krahun e djatht, pas një ngjitje Djurën (Xhyrën), ndërsa një lum i vogël Palareka(?), bie pothuajse përpendikular gjer te rruga, nëpërmes shkëmbinjsh që sundojnë rrëpira masive të veshura me pemë, mjerisht të djegura nga vllehët nomadë, për të kullotur kopetë e tyre (fenomen $i$ cili ndodh edhe në ditët tona)." Gjatë ekskursionit të tij, autori, përshkruan me 


\section{Albanon}

\section{Revistë kulturore}

detaje luginën e Shkumbinit "tepër e ngushtuar, tepër e thellë, nëpër të cilën rrjedh Gostima, e cila del nga një grykë e ngushtë e derdhet në Shkumbin, pranë urës që çon në krahun e djathtë”. Jep gjithashtu, disa të dhëna për Urën e Bekiari (Beqarit), me përmasa mjaft të mëdha në gjatësi me kalldrëm e gjërësi $4.5 \mathrm{~m}$. dhe me katër harqe. "Më pas udha kalon nëpër një fushë të vogël mbjellë me orizore, depërton përmes një zabeli me rrepe gjatë shtratit të lumit, por duke qenë se lugina ngushtohet, udha ngjitet nëpër shkëmbij dhe pastaj drejt Elbasanit, ku veçse një distancë e vogël e ndan qytetin nga Ura e Madhe në rrugën e Berahut(!). Kjo urë është e gjatë 350 hapa, me 11 harqe dhe me sipërfaqe të rrafshët. Mbresëlënës tingëllon edhe përshkrimi që ai i bën Elbasanit, fushës së tij, e mbjellë si duhet, sasia e madhe e pemëve frutorë, rrethuar nga plantacione ullinjsh që shërbejnë njëkohësisht për kullotë e disa herë për varrezat e turqve... Në qytet bie në sy, në formë drejtkëndëshi një hapësirë rrethuar me qiparise shekullorë ku herëpashere mblidhedhin qytetarët myslimanë për ceremoni fetare. Tregu i mbushur me dyqane, sidomos ato të ëmbëltoreve, prodhime armësh me qytë druri veshur me metal etj. Siç e përshkruan konsulli francez : "Qyteti ka dy lagje të krishtera, një të banuar nga shqiptarë të ritit oriental, e dyta nga vllehë, me nga një kishë e shkollë më vete. Kajmekani është një bej vendas. Nëpër qytet edhe gratë e krishtera dalin të mbuluara me perçe dhe me kostum turk, dhe po ashtu si myslimanet, ato nuk u shfaqen vizitorëve. Drejt rrugës për në Tiranë, në fund të kopshteve, rrjedh një lumë me shtrat të gjerë e ujë të pakët Geramika (Zaranika), mbi të cilën kalon një urë guri me dy harqe që kalon nëpër një luginë të ngushtë, rrethuar me ullinj, drejt luginës së Kuthësit, e pastaj nëpër një shteg të pjerrët të Grabit(!), ngjitesh në majë, në drejtim të veriut, nëpër tokë rreshpore, drejt Tiranës". Megjithëse disa toponime si "rruga e Berahut" apo "Grabi”, ne na duken të panjohura, materiali i Ogust Dozon, shoqërohet edhe me një gravurë të tregut të Elbasanit. Në shkrimet e këtij libri të vyer, ndihen jehonat e ngjarjeve historike, rrebeshet e kohës, tymnajat e mbijetesës, rrezëllime shpirtërore, që mbeten udhërrëfyese për të shkuarën tonë edhe sot.

-Lehon Kahun (1841-1900), shkrimtar i njohur.

Një nga librat e tij më të sukseshëm, vlerësuar edhe nga Akademia Franceze, mbetet romani Hasan Jeniçeri-historia e një shqiptari më 1516, të cilin poeti dhe shkrimtari i shquar francez, Apoliner, do ta konsiderojë "Njëlloj kryevepre ....nga historia e shqiptarëve”. Nuk do të zgjatemi në përmbajtje, por është me shumë kureshtje të veçojmë se personazhi kryesor i Kahun është elbasanas, gjë që e deklaron edhe vetë në roman “kam lindur në Elbasan”, duke cituar më pas, "elbasanasit janë shqiptarë të vërtetë, të paaftë për të gënjyer e mashtruar, 
e që flasin gjuhën e pastër dhe të vërtetë shkipe (shqipe)". Po ashtu, në roman hasen dhe fjalë të urta vendase të asaj kohe, si: turk Kostandinopoje, shqiptar Elbasani dhe pazar Elbasani, ku tregtari nuk gënjen e nuk e mashtron blerësin. Shkrimtari përshkruan dhe qytetin e Elbasanit, shtëpitë karakteristike me çati të kuqe në formë piramidash të ulta, disa në formë kulle, me taracë me bedena nga ku shihej nga sipër lugina Shkumbit (Shkumbinit), me ujë të turbulluar. Në qytet binin në sy tri xhami me minare të bardha dhe kupola të veshur me plumb, një kishë me kullën tetëkëndore; në anën tjetër nga perëndimi, dukeshin fushat me elb, shqopishte e shkurre me bush, nga pas vreshtat, e më sipër kullota; në veri të kodrave, kisha e Shën Joanit, mes të cilave gjarpëron rruga për Tiranë. Përpos këtij përshkrimi gjeografik, heroi i romanit, ndalet në përshkrimin me nostalgji të vendlindjes, Elbasanit, shtëpisë kullë të të atit, jetesës prej të krishteri, me emrin Jurgi, apo rrethit shoqëror. "Nga dhjaku i kishës, një grek i quajtur Kristoforides (autori mund të ketë bërë analogji edhe me emrin e Kristoforidhit, pavarësisht që ngjarjet në roman datojnë mbi 200 vjet para lindjes së tij), mësova të shkruaj e të këndoj në gjubën helenike dhe turke, derisa ia arritën qëllimit rekrutimin tim jeniçer, me këmbënguljen e Xheladin Beut të Elbasanit, që do të thoshte, i rekrutuar në emër të Padishahut, një qese me njëqind dukatë të florinjta (qü në qoftë se vritej apo plaçkitej të mos qaheshin se nuk i gjetën gjë), babai, fisniku Trank Spiro, më bekoi, Allah! Perëndisë i qofshim falë, u nisëm ndoshta për mos u kthye më".

Në shumë faqe të tjera të kësaj Antologjie monumentale, me autorë të shquar francezë, përshkruhet gjerë e gjatë edhe një udhëtim në Shqipërinë e Mesme (1897), nga:

-Viktor Berar (1864-1931), senator gjatë Republikës së III-të, studiues, profesor dhe përkthyes. Ai është autor i disa librave për Perandorinë Osmane si: Sulltani i Kuq, Turqia dhe helenizmi bashkëkohor etj, duke marrë në mbrojte të drejtat e popujve që përbënin këtë Perandori, në mënyrë të veçantë atë shqiptar. Në shënimet e tij të udhëtimit në Shqipërinë e Mesme, po evidentojmë ato më me interes, sidomos për Elbasanin. "Kilometër pas kilometri, pasi lemë bregun e Durrësit, kalojmë nëpër Kavajë, drejt Elbasanit, ku na u desh të ndalemi për t’u shlodhur, si ne, ashtu dhe kafshët. Ndryshe nga qytetet e tjera, Elbasani mund të bëhet një qendër e madhe, sepse pykëzimi i lumit, gjithnji ka qenë e mbetet rruga drejt Maqedonisë, rruga e përjetëshme romake nga Adriatiku në Arqipel. Nga ana tjetër, këtu kryqëzohet rruga tjetër e madhe që vjen nga veriu për në jug". Për qytetin shkruhet se "është rreth $150 \mathrm{~m}$ mbi nivelin e detit, mes pyjesh të larmishëm, ujëra të bollshëm, toka të pasura, nën një klimë të butë, duket si e bërë për jetesën e një popullsie 


\section{Albanon}

\section{Revistë kulturore}

të shumtë. Ky qytet përbëhet nga tri lagje me popullsi prej tri shtresash koncentrike: në qendër, në muret e një kështjelle të lashtë, jetojnë 150-200 familje me 750-800 individë; përreth një dendësi myslimanësh prej 500600 shtëpi, me 2000-3000 individë; në rrethina, një riveshje me 160-180 shtëpi valake me rreth 800 të krishterë. Duhet shtuar se tërë ky popull, myslimanë e të krishterë, në Elbasan jetojnë në bashkëqytetësi. Fenomeni i ndryshimit të fesë, bëhej më tepër për privilegje, ndërsa për helenizim, kjo ishte e pavend dhe e pakuptimtë. Përshkruhet kalaja e qytetit, e rrethuar me mure të bukur të epokës romake apo bizantine me gurë dhe me tulla, që pas vitit 1830, muret filluan të shërbejnë si barrierë. Kisha brenda kalasë, daton para tetëdhjetëvjetësh, është një godinë e gjatë guri me kryet trefish rrethorë. Rretheqark kishës, janë varreza të cilat respektohen shumë nga të afërmit, sidomos nga gratë, të veshur me shall të bardhë e me ferexhe të zeza mbi çitjanet e potina të verdha”.

Më gjerësisht, autori përshkruan ritet e ceremonitë fetare të krishterëve, që ndiqeshin me respekt nga gjithë bashkësia e lagjes, si pagëzimin e fëmijëve, përkujtimin e Ditës së Ringjalljes së Krishtit, ritet në kujtim të të afërmve të vdekur, me blatesa të shenjta, kanistra me kuleçë, një tas me cironka, një gatesë përzier me bajame, oris, rrush të thatë e grurë. Një llambadhe digjet, vendosur mbi kokën e varrit. Aty-këtu ndëgjohej psherëtima melankolike, jo vaje e kuje, sikurse hasëm në vende të tjera, por "ku vjen dallëndyshja të më flasë për pranverën dhe bilbili të më sjellë majin e bukur" e të tjera. Ndërkohë, në Antologjinë në fjalë, përbën mjaft interes një shkrim në gazetën "Elbasani", të ditës së mërkurë, 26 Vjeshtë e I-rë 1923, me titull "Kujt i përket Manastiri i Shën Naumit? Shqypniës? Serbies? ", shkruar nga:

-Justin Godar dhe marrë nga gazeta franceze Le Matin. Shkrimin po e botojmë, pa korigjim ortografik për të respektuar shtypin e kohës. Ja momentet esenciale të tij: Në fillesën e shekullit X kallugjeri (murgari) Naum, nëxans $i$ Cirilit e Methodit, qe dërguë prej carit Boris, me misjon e u vendos në brigjet e liqenit Ohrisë. Nga sjellja e puna e palodhur e tij, fitoi autoritet e u adhure dhe e vunë në rradhë të shejtnave, u ngreh ndërtesa e mori emrin: Manastiri i Shën Naumit (në shek XIV). Nga vetë pozicjoni e vlerat që ka, u bë vazhdimisht mollë sherri midis Serbisë që e pushtuan dhe Shqypnisë. Dikur Komisioni i Fuqive të Mëdha, njoftoi se Monastiri ishte tokë shqiptare, ankimet dhe sherret vazhduan! Komision pas komisioni, ndërruan opinion, por siç lexon artikulli një gjë është e qartë: "nderimi besimtar i Shën Naumit prej shumë kohe, qe pranu e nderue me shum dashuni prej shqiptarëve" por përfundimi dihet, "të shtetit ma të vogël e ma të ligësht ishte nji mëkat”... U baftë që prej atje nalt shpirtmirë 
Shën Naumi i ndriçonte ata të Konferencës së ambasadorëve me arsyetim e me mendje të qëndrueshme siç e ka vetë".

Ndërkohë, krahas teksteve vlerësuese, në faqete antologjisë Pena të arta franceze për shqiptarët (1332-2007), kanë zënë vend edhe vepra të artit figurative të autorëve francezë, për Shqipërinë dhe shqiptarët. Kështu, në kopertinë është tabloja e piktorit francez, Aleksandre Marie Colin, e vitit 1831, Bajroni si Don Zhuan me Haidenë, portrete të shumta për Skënderbeun, gravura të librave shkruar për Skënderbeun, portreti i Donika Kastriotit, i Theodore de Bry, tablo të Jost Amman(1577), për betejat $e$ Skënderbeut e kthimin e tij në Krujë, të piktorit Paul Conard Balthasar, më 1686, që pasqyron skenën e një dyluftimi të Skënderbeut, të Caton R. Woodeville, 1910, Festa e luleve etj. Por në pikturat franceze, preken edhe tematika të tjera, si portrete shqiptarësh nga krahina të ndryshme, apo ushtarësh. Vijon Coro J. Gordon, me tablonë Tregu i Elbasanit (1927), si edhe E. Lear me disa peizazhe: Perëndimi në Himarë; qyteti i Beratit (1848); Selvitë e Elbasanit; Shpatarakë dhe Varrezat e Elbasanit, E. Durham (1909) etj. Antologjia përmban veç këtyre edhe poezi, sonete, deri fragmente operash, nga autorë francezë : soneti për Skënderbeun, nga Pier dë Ronsar (1524-1585), "O shqiptar prej fatit sjellë"; Opera "Skënderbeu”, tragjedi në 5 akte nga Antuan Hudart dë la Mot (1672-1731), muzikuar nga Fransua Frënker dhe Fransua Rebel, kompozitorë të Dhomës Mbretërore, që u shfaq për herë të parë më 27 tetor 1735 etj. Interes të veçantë në këtë libër, përbëjnë edhe citimet e poemave të njohura të shkrimtarit të madh francez, Viktor Hygo, "Dervishi" dhe "Kështjella" (për Ali Pashë Tepelenën), apo dhe vepra e Aleksandër Dumasë "Kujtime”, shkruar më (1852-1856).

"Pena të arta franceze për shqiptarët", nuk ka lënë jashtë vëmendjes edhe lidhjet në kohëra midis Francës dhe Shqipërisë. Çeljen dhe funksionimin e Liceut francez të Korçës, apo kryerjen e studimeve në Francë të një sërë figurash të Akademisë së Shkencave,disa prej të cilëve, si: Dhimitër Shuteriqi, Kolë Paparisto, Mahir Domi, nga Elbasani. 